G6PD gene containing the polymorphisms 202G $>A$ and $376>G$ was amplified by PCR followed by sequencing.

Results Malaria prevalence was 22 (10\%). With regard to G6PD analysis, it was found that 206 patients had G6PD genotype available including 74.8\% (154/206) with G6PD normal, $12.1 \%(25 / 206)$ with heterozygous genotypes and 13.1\% (27/ 206) with G6PD deficiency [11.6\% (24/206) were male hemizygous and $1.4 \%(3 / 206)$ were female homozygous]. Data are further analysed to investigate the association between G6PD genotype, uncomplicated malaria, haemoglobin concentration as well as parasite densities.

Conclusion A high prevalence of G6PD deficiency is reported for these Congolese children. Further investigation with larger sample size in different areas of the country is needed to design future and adapted interventions.

\section{PO 8529 INTRODUCING A UNIQUE RESEARCH CAPACITY DEVELOPMENT PLATFORM SUPPORTING PREPAREDNESS FOR EFFECTIVELY COMBATING EPIDEMIC OUTBREAKS}

Nina Jamieson*, Trudie Lang. University of Oxford, UK

\subsection{6/bmjgh-2019-EDC.131}

Background In 2013, WHO stated that unless low-income countries become the generators, rather than the recipients, of health research data there will never be any real improvement in the devastating public health challenges these countries face. The Global Health Network was cited as an important agent for change in addressing this need.

The Global Health Network built an innovative digital platform, generating and supporting communities of practice focused on global health research. We have established a vast online knowledge-sharing resource, so far visited by more than 1.5 million frontline healthcare workers and researchers globally. Over 400,000 times online modules were taken by users from our target countries using our Training Centre, which offers a wide range of high-quality research skills courses. We also support skills development through regionally-led activities. Here we present how our approach is applied to support preparedness for epidemic outbreaks in Africa.

Methods A community of practice was set up for the EDCTP2 ALERRT programme on The Global Health Network platform (https://alerrt.tghn.org/). It provides a mechanism for research staff to work together, share ideas, methods and approaches to foster knowledge exchange and collaboration. The ALERRT community of practice platform hosts training courses, help topics, templates, guidance - everything that is needed to run a good clinical study. The initial set of resources is available now, others are being developed following the knowledge gap analysis. In addition, our online platform offers free participation in the Professional Development Scheme - a unique framework to track research skills development.

Results The ALERRT capacity development community of practice was launched in April 2018. We will present how this regionally-championed initiative is being taken up and what difference it is already making to the community of researchers.

\section{PO 8536 BIOMEDICAL ETHICS AND REGULATORY CAPACITY BUILDING PARTNERSHIP FOR PORTUGUESE-SPEAKING AFRICAN COUNTRIES (BERC-LUSO)}

${ }^{1}$ Maria do Céu Patrão Neves*, ${ }^{2}$ Maria A Ribeiro, ${ }^{3}$ Ana S Carvalho, ${ }^{3}$ Joana Araújo, ${ }^{4}$ Sofia Oliveira Martins, ${ }^{1}$ Ana P Martins, ${ }^{1}$ Filipe Mota Helder, ${ }^{1}$ Luís Rhodes Baião, ${ }^{1}$ Jorge Batista, ${ }^{5}$ Joana De Morais Afonso, ${ }^{6}$ Katiza Mangueira, ${ }^{7}$ Carla D Reis, ${ }^{8}$ Cunhate Na Banga, ${ }^{9}$ Tânia Sitoie. ${ }^{1}$ Ordem dos Farmacêuticos, Lisbon, Portugal; ${ }^{2}$ Comissão de Ética para a Investigação Clínica, Lisbon, Portugal; ${ }^{3}$ Universidade Católica Portuguesa - Instituto de Bioética, Porto, Portugal; ${ }^{4}$ Infarmed - Autoridade Nacional do Medicamento e Produtos de Saúde I.P., Lisbon, Portugal; ${ }^{5}$ Instituto Nacional de Saúde Pública do Ministério da Saúde de Angola, Luanda, Angola; 'Direção Nacional de Medicamentos e Equipamentos do Ministério da Saúde de Angola, Luanda, Angola; ${ }^{7}$ Agência de Regulação e Supervisão dos Produtos Farmacêuticos e Alimentares, Cabo Verde; ${ }^{8}$ Comité Nacional de Ética em Pesquisa em Saúde do Instituto Nacional de Saúde Pública do Ministério da Saúde Pública da Guiné Bissau, Bissau, Guinea Bissau; ${ }^{9}$ Departamento Farmacêutico do Ministério da Saúde de Moçambique, Maputo, Mozambique

10.1136/bmjgh-2019-EDC.132

BERC-Luso is a project for building Ethics and Regulatory Capacity, to be developed in four sub-Saharan African countries: Angola, Guinea-Bissau, Mozambique and Cape Verde, and to be implemented in 2018-2021. National Ethics Committees (NECs) and National Regulatory Authorities (NRAs) have been engaged ( 6 institutions) with the partnership of 4 Portuguese institutions (experts in ethical review and regulatory supervision).

Considering that: 1) clinical trials are fundamental to improve healthcare and develop biomedical research; but 2) can only take place within regulatory systems and under ethical review protocols; and 3) some African countries still lack an adequate legislative framework and the expertise to assure good ethical review and regulatory supervision, it is urgent to change the current situation.

The BERC-Luso project will unfold at four different levels, each aiming at a specific goal in converging dynamics.

1. Legislative level: Presentation of a comparative study of the Portuguese Speaking African Partner Countries' legislation on NECs and NRAs with recommendations for revision in compliance with the international requirements. The goal is to promote adequate internationally recognised legislation.

2. Educational level: Implementation of an intensive and comprehensive Education Programme, both theoretical and practical, reflexive and normative, ethical and legal, addressing the needs of the countries involved, within their cultural contexts, and in their own mother tongue. The goal is to promote capacity building.

3. Training level: Organisation of intensive internships, demanding participants to accurately apply everything they have learned to their everyday practice. The goal is to have knowledgeable and skilled experts.

4. Networking level: Build powerful digital tools to connect partner institutions, staff and participants during the project and beyond, creating a digital repository of documents, and different tools for ethical and regulatory evaluation.

These actions converge to provide internationally recognised legislation and expertise for the development of biomedical research for the benefit of the population. 